\title{
Correlation of Prerequisite Course Grades with Student Performance
}

\section{Dr. Amir Karimi, University of Texas, San Antonio}

Amir Karimi is a Professor of Mechanical Engineering and the Associate Dean of Undergraduate Studies at The University of Texas at San Antonio (UTSA). He received his Ph.D. degree in Mechanical Engineering from the University of Kentucky in 1982. His teaching and research interests are in thermal sciences. He has served as the Chair of Mechanical Engineering (1987 to 1992 and September 1998 to January of 2003), College of Engineering Associate Dean of Academic Affairs (Jan. 2003-April 2006), and the Associate Dean of Undergraduate Studies (April 2006-present). Dr. Karimi is a Fellow of ASME, senior member of AIAA, and holds membership in ASEE, ASHRAE, and Sigma Xi. He has served as the ASEE Campus Representative at UTSA, ASEE-GSW Section Campus Representative, and served as the Chair of ASEE Zone III (2005-07). He chaired the ASEE-GSW section during the 1996-97 academic year.

\section{Dr. Randall D. Manteufel, University of Texas, San Antonio}

Randall Manteufel is an Associate Professor in Mechanical Engineering at the University of Texas at San Antonio. He teaches courses in thermodynamics, fluid mechanics and heat transfer. He is the faculty advisor for the student chapter of American Society for Heating Refrigerating and Air-Conditioning Engineers at UTSA. 


\title{
Correlation of Prerequisite Course Grades with Student Performance
}

\begin{abstract}
The relationship between the depth of knowledge gained in a course and grades issued from various instructors teaching the same course is examined in this paper. One way to gage the depth of knowledge gained by students completing a particular course is to track their performance in the follow up courses in which a full understanding of the prerequisite topics are essential. A course sequence in thermodynamics is an ideal vehicle for such an examination, since a complete knowledge of the materials covered in the first course is essential for the successful completion of the second course. Between fall semester 1994 and fall 2012, the first course in thermodynamics was offered 55 times and taught by nine instructors. An examination of grade distributions in this course shows that there are small variations in student passing rates for a given instructor from semester to semester. The grade distributions, however, display significantly wider variations of student passing rates among the instructors who have taught the course. Average student passing rates have been as low as $36 \%$ for the sections taught by one instructor and as high as $81 \%$ for the sections taught by another instructor. On the surface it is not clear whether the higher passing rate is the result of superior teaching skills or due to a more lenient grading policy. Therefore, the same grade awarded by different instructors, might not be a good indication of the knowledge gained by students completing the course. This paper examines students' performance in a second course in thermodynamics. This study tracks groups of students that have taken the first course in thermodynamics from one instructor and examines their performance in the second course in thermodynamics.
\end{abstract}

\section{Introduction}

Grades are usually used to measure student success in the college education. For this reason, grade point average (GPA) plays a major factor for awarding scholarships, admitting students to graduate schools, and considering graduates for employment in the industry. Since the overall GPA is based on the average of the grades received in a collection of courses taken by a student, it might be a valid tool for measuring the acquisition of knowledge and skills of that student. However, studies $[1,7]$ have shown that grade distributions vary significantly among the faculty members teaching the same course at the same institution. Therefore, a grade received in a single course might not necessarily signify the level of student knowledge and competency in the topics covered in that course.

One way to gage the depth of knowledge gained by students completing a particular course is to track their performance in the follow up courses in which a sound understanding of the prerequisite topics are needed. A course sequence in thermodynamics is an ideal vehicle for such an examination. A full understanding of the materials covered in the first course is essential for the successful completion of the second course.

All mechanical engineering degree programs in the United States require at least one course or a two course sequence in thermodynamics. The requirement is typically either a single 3 or 4 semester hour $(\mathrm{SCH})$ course or a two-semester course sequence in thermodynamics, totaling 6 $\mathrm{SCH}$. Many of those programs requiring a single course, also offer a second course in 
thermodynamics as an elective. In a two-semester course sequence, the first course focuses on the fundamental concepts and the second course focuses on applications and more advanced concepts. Some programs with a single required course offer students an opportunity to take a second course in applied thermodynamics as an elective.

The mechanical engineering degree program at The University of Texas at San Antonio (UTSA) requires a two-semester course sequence in thermodynamics: ME 3293-Thermodynamics-I and ME 4293-Thermodynamics II. The focus of the first course is on the fundamental concepts, where students are introduced to such definitions and fundamental concepts as thermodynamic systems, extensive or intensive properties, conservation of mass and energy, and the second law of thermodynamics. Students are also learn how to use tables, charts, or appropriate equations to evaluate thermodynamic properties. In addition basic power, refrigeration, and heating cycles are included to demonstrate the application of the fundamental concepts. The second course concentrates on the application of fundamental concepts and laws. The coverage includes exergy analysis, the analysis of more advanced thermodynamic cycles, property relationships, study of gas mixtures, psychrometric applications, combustion processes, and chemical/phase equilibrium.

Historically, the first course in thermodynamics is more difficult for the students to pass. One measure of difficulty is the unsuccessful attempt rate. At UTSA all required mathematics, science, and engineering courses must be completed with a grade of " $\mathrm{C}$-" or better. Therefore, the successful attempt rate is defined as the percentage of students enrolled in the class on the census date who complete the course with a passing grade of "C-" or better. Those students who withdraw from the class after the census date and receive a grade of "W". Therefore a simple metric for unsuccessful attempt in a course is the percentage of students who receive grades of $\mathrm{D}+, \mathrm{D}, \mathrm{D}-, \mathrm{F}$, or W (DFW percentage) in a given class.

Between fall semester 1994 and fall 2012, one or two sections of ME 3293-Thermodynamics-I were offered 55 times and taught by nine different instructors. The course was offered every spring and fall semester, and in most summer sessions, but not all. In the last two years more than one section of the course has been offered during fall and spring semesters. Figure 1 displays the percentage of grades of $\mathrm{A}+, \mathrm{A}, \mathrm{A}-, \mathrm{B}+, \mathrm{B}, \mathrm{B}-, \mathrm{C}+, \mathrm{C}$ and $\mathrm{C}-(\mathrm{ABC}$ rate) assigned by the instructors for each section during this period. It should be noted that until fall 2011, the grading scales did not include "+" or "-" letter grades. In Fig. 1, the instructors are identified as Inst-1 through Inst-9. An examination of grade distributions shows that there are small variations in passing rates for a given instructor from semester to semester. A higher passing rate for an instructor for one semester may be due to an uncommonly good pool of students. The grade distributions in Fig.1, however, reveals much wider variation of passing rates among the nine different instructors who have taught Thermodynamics-I in the period being considered. Student passing rates have been as low as $24 \%$ for a section taught by one instructor and as high as $92 \%$ for another section taught by another instructor. The first two instructors have taught the majority of classes. The ABC rate is comparable for the Inst-1 and Inst-2. Instructor-3 taught the course for a few years and had a reputation for being a rigorous instructor who had uncommonly low $\mathrm{ABC}$ rates which were usually in the 30\% range. Instructor 6 who has taught 6 sections of the course has a reputation among the students for being easy. In order to have a more uniform scale for the assessment of student knowledge, Inst. 6 collaborate with Instructors 1 and 
2 in fall semester 2011, in writing the exam questions and grading exams [8]. Figure 1 shows that the $\mathrm{ABC}$ rate for the Inst- 6 sharply dropped during that semester.

On the surface it is not clear whether the higher passing rate is the result of superior teaching skills or due to a more lenient grading policy. Therefore, the same grade awarded by various instructors, might not be a good representation of the depth of knowledge gained by students completing the course. To find an answer to the question whether grades assigned by various instructors teaching the same course accurately represents the students' depth of knowledge, this paper examines students' performance in the second course in thermodynamics. The paper will track each group of students who has successfully completed ME 3293 with one of the instructors and examine their performance in ME 4293. The results are analyzed and discussed in this paper. Methods employed by instructors for assessing students' knowledge and assigning grades are briefly discussed.

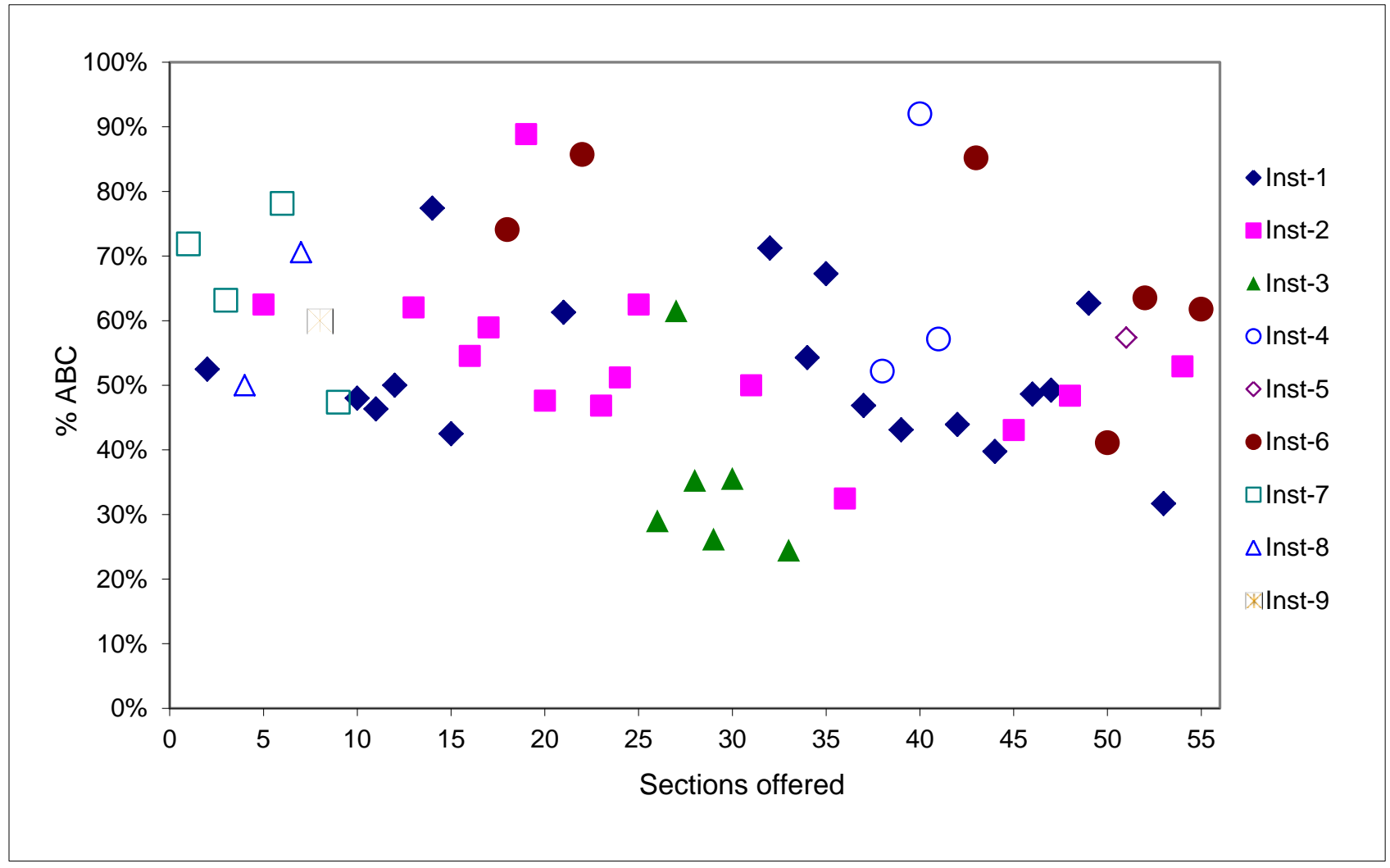

Fig. 1 Percentage of passing grades (A, B, and C) in ME 3293 from fall 1994 through fall 2012.

\section{Instructor Influence on Passing Rate}

As suggested by Fig 1, the grade distribution differs among instructors teaching the same course. Therefore, the passing rate is influenced by the instructor who is teaching the course. Grade distributions for ME 3293-ThermodynamicsI and ME 4293-Thermodynamics II are presented and discussed in the following sections. 


\section{A. ME 3293: Thermodynamics-I}

As indicated earlier, nine different instructors taught ME 3293 between fall semester 2004 and fall semester 2012. There have been 2445 attempts by 1545 students during this period. A total of 978 students $(63 \%)$ attempted the course once, 349 (23\%) attempted twice, 149 (10\%) attempted three times, $46(3 \%)$ attempted four times, $12(1 \%)$ attempted five times, $5(0.3 \%)$ attempted six times, $2(0.1 \%)$ attempted seven times, $2(0.1 \%)$ attempted eight times, and 2 $(0.1 \%)$ attempted the course 9 times. It should be noted that the number of students for each attempt category does not indicate that all students in that category have passed the course. For example, the 978 students who attempted the course once, include those students in fall 2012 sections who did not pass the course, but have not attempted the course for the second time. The College of Engineering has recently established a new policy forcing students to change their major if they do not pass a course within three attempts. The points awarded for each letter grade is included in table 1. These points are used for the evaluation of grade point average (GPA)

The grade distribution for combined sections of the ME 3293 offered between fall semester 1994 and fall semester 2012 is presented in Table 1. The table shows that for the combined sections, $52.7 \%$ of students completed the course successfully and $47.3 \%$ students were unable to do so. One student challenged the course and received credit (CR) for the course and no grade was reported (NR) for two students.

Table 1. Cumulative grade distribution for all sections of ME 3293 taught between fall 2004 and fall semester 2012

\begin{tabular}{|c|c|c|c|}
\hline Grade & Points & Numbers receiving the grade & \% of the total receiving the grade \\
\hline A + & 4.00 & 5 & $0.2 \%$ \\
\hline A & 4.00 & 254 & $10.4 \%$ \\
\hline A- & 3.67 & 4 & $0.2 \%$ \\
\hline B + & 3.33 & 1 & $0.0 \%$ \\
\hline B & 3.00 & 393 & $16.1 \%$ \\
\hline B- & 2.67 & 8 & $0.3 \%$ \\
\hline C+ & 2.33 & 6 & $0.2 \%$ \\
\hline C & 2.00 & 608 & $24.9 \%$ \\
\hline C- & 1.67 & 10 & $0.4 \%$ \\
\hline D+ & 1.33 & 3 & $0.1 \%$ \\
\hline D & 1.00 & 320 & $13.2 \%$ \\
\hline D- & 0.67 & 0 & $0.0 \%$ \\
\hline F & 0 & 368 & $15.1 \%$ \\
\hline W & 0 & 461 & $18.9 \%$ \\
\hline CR & None & 1 & $0.0 \%$ \\
\hline NR & None & 3 & $0.1 \%$ \\
\hline Total ABC & & $\mathbf{1 2 8 9}$ & $\mathbf{5 2 . 7 \%}$ \\
\hline Total DFW & & $\mathbf{1 1 5 2}$ & $\mathbf{4 7 . 3 \%}$ \\
\hline Other & & $\mathbf{0 . 1}$ \\
\hline
\end{tabular}


The grade distributions for each instructor of ME 3293 are shown in Table 2. Of the nine instructors, five have been tenured/tenure-track (TT) faculty and the other four have been on non-tenure track (NTT), teaching courses on a part-time basis. Table 2 identifies the number of semesters taught and includes the total number students for each instructor. The \% $\mathrm{ABC}$ represents the total percentage of grades of $\mathrm{A}, \mathrm{B}$, and $\mathrm{C}$ and \% DFW is the total percentage of grades of $\mathrm{D}, \mathrm{F}$, and $\mathrm{W}$ for the sections taught by each instructor. The percentages for each letter grade also includes both "+" and "--" letter grades. For example, the percentages presented for A grades include all A+, A, and A- grades. Two types of grade point averages are included in Table 2. The column identified as GPA represents the standard course grade point average, where grades of $\mathrm{W}$ do not have any influence on the values of GPA. The standard GPA might be misleading for the evaluation of the success rate in completing a course, since a grade of $\mathrm{W}$ still represents an unsuccessful attempt. Since UTSA has a very generous drop date policy, allowing students to drop courses until near the end of the semester, many students drop the course because they are doing poorly and are likely to earn a failing grade if they remain in the class. Hence, the class grade point average could have been lower than values reported in the GPA column if students stayed in the course until the end of the semester. To provide a better measurement for comparison, grades of $\mathrm{W}$ and $\mathrm{F}$ are treated the same for the evaluation of class grade point average and the results are reported in Table to as GPAW.

Table 2. Cumulative grade distribution for sections of ME 3293 taught by each instructor

\begin{tabular}{|c|c|c|c|c|c|c|c|c|c|c|c|c|c|}
\hline $\begin{array}{c}\text { Inst } \\
\#\end{array}$ & $\begin{array}{c}\text { Inst- } \\
\text { Type }\end{array}$ & $\begin{array}{c}\text { \# of } \\
\text { semesters }\end{array}$ & $\begin{array}{c}\text { \# of } \\
\text { students }\end{array}$ & $\begin{array}{c}\% \\
\text { A }\end{array}$ & $\begin{array}{c}\% \\
\text { B }\end{array}$ & $\begin{array}{c}\% \\
\text { C }\end{array}$ & $\begin{array}{c}\% \\
\text { D }\end{array}$ & $\begin{array}{c}\% \\
\text { F }\end{array}$ & $\begin{array}{c}\% \\
\text { W }\end{array}$ & $\begin{array}{c}\% \\
\text { ABC }\end{array}$ & $\begin{array}{c}\% \\
\text { DFW }\end{array}$ & GPA & GPAW \\
\hline 1 & TT & 18 & 925 & 10 & 15 & 26 & 14 & 16 & 18 & 52 & 48 & 1.86 & 1.52 \\
\hline 2 & TT & 14 & 538 & 13 & 17 & 22 & 14 & 9 & 27 & 50 & 50 & 2.12 & 1.55 \\
\hline 3 & TT & 6 & 250 & 4 & 14 & 18 & 13 & 34 & 17 & 36 & 64 & 1.30 & 1.08 \\
\hline 4 & TT & 3 & 179 & 12 & 13 & 35 & 13 & 16 & 11 & 60 & 40 & 1.92 & 1.70 \\
\hline 5 & TT & 1 & 61 & 13 & 17 & 28 & 9 & 8 & 25 & 58 & 42 & 2.26 & 1.67 \\
\hline $\begin{array}{l}\text { TT } \\
\text { Cumulative }\end{array}$ & $\mathbf{4 2}$ & $\mathbf{1 9 5 3}$ & $\mathbf{9}$ & $\mathbf{1 5}$ & $\mathbf{2 5}$ & $\mathbf{1 3}$ & $\mathbf{1 6}$ & $\mathbf{2 0}$ & $\mathbf{5 0}$ & $\mathbf{5 0}$ & $\mathbf{1 . 8 7}$ & $\mathbf{1 . 5 0}$ \\
\hline 6 & NTT & 6 & 306 & 13 & 21 & 27 & 12 & 12 & 14 & 61 & 39 & 2.12 & 1.81 \\
\hline 7 & NTT & 4 & 121 & 15 & 18 & 34 & 9 & 11 & 13 & 67 & 33 & 2.20 & 1.93 \\
\hline 8 & NTT & 2 & 49 & 24 & 10 & 22 & 12 & 12 & 18 & 57 & 43 & 2.28 & 1.86 \\
\hline 9 & NTT & 1 & 15 & 13 & 27 & 20 & 13 & 7 & 20 & 60 & 40 & 2.33 & 1.87 \\
\hline $\begin{array}{l}\text { NTT } \\
\text { Cumulative }\end{array}$ & $\mathbf{1 3}$ & $\mathbf{4 9 1}$ & $\mathbf{1 4}$ & $\mathbf{1 9}$ & $\mathbf{2 8}$ & $\mathbf{1 2}$ & $\mathbf{1 2}$ & $\mathbf{1 4}$ & $\mathbf{6 2}$ & $\mathbf{3 8}$ & $\mathbf{2 . 1 6}$ & $\mathbf{1 . 8 4}$ \\
\hline $\begin{array}{l}\text { TT and } \\
\text { NTT }\end{array}$ & $\mathbf{5 5}$ & $\mathbf{2 4 4 4}$ & $\mathbf{1 0}$ & $\mathbf{1 6}$ & $\mathbf{2 5}$ & $\mathbf{1 3}$ & $\mathbf{1 5}$ & $\mathbf{1 9}$ & $\mathbf{5 3}$ & $\mathbf{4 7}$ & $\mathbf{1 . 9 3}$ & $\mathbf{1 . 5 7}$ \\
\hline
\end{tabular}

A comparison of the data in Table 2 shows that the DFW rates for the sections taught by NTT instructors are generally lower than those taught by the TT instructors. The data suggests that collectively the tenure track faculty have been harder graders than their NTT counterpart. Table 2 shows a DFW rate of $47 \%$ for TT faculty as compared to $38 \%$ for NTT faculty. This indicates that those students who took the course with a NTT faculty had a much higher chance of passing the course. The data also suggests that Inst- 3 is the harshest grader among the nine instructors. The DFW rate was the highest for Inst-3 (64\%), as a result sections taught by Inst-3 had the lowest GPAW (1.08). Instructors 1 and 2 have taught the largest number of sections and with 
the greatest number of students. Their DFW rates are similar and interestingly the course GPAW values for these two instructors are almost the same.

As stated earlier, Inst- 6 has a reputation among the students for being easy especially during first three times that he taught the course. The grade distribution history for sections of ME 3293 taught by Inst-6 is displayed in Table 3. The grade distribution for all NTT instructors as well as combined TT and NNT instructors are included in the last two rows for comparison. The table clearly shows that Inst-6, during the first three semester of teaching the course, has been the most lenient grader among the nine instructors. It shows an ABC rate of $81 \%$, a class GPA of 2.73, a class GPAW of 2.55 for Inst-6 as compared to an ABC rate of 53\%, course GPA of 1.93, and course GPAW of 1.57 for all instructors teaching the course. In order to have a more uniform scale for the assessment of student knowledge, Inst- 6 collaborated with Instructors 1 and 2 in fall semester 2011, in writing the exam questions and grading exams [8]. At the beginning of this collaboration, before the start of semester, it was noted that Inst- 6 gave open book exams when he taught the course for the first three times, while instructors 1 and 2 were giving closed book exams, but provided all equations needed for the exams. It was agreed that Inst- 6 follow the policy of closed book exams, since the textbook contains too many solved examples, and therefore most exam questions would be very similar to the examples in the textbook. All three instructors collaborated in suggesting exam questions, but Inst- 6 had the final decision on selecting the exam questions. All exam problems were graded by instructors 1 and 2, where each instructor was responsible for grading an individual problem for all students in order to maintain uniformity in grading scale. During the collaboration, Inst-6 commented that he was giving higher partial credit in the past than the partial credit given by other two instructors who graded the exam problems this se during that semester. Instructor- 6 indicated that he seldom gave less than $50 \%$ credit on a problem in the past. Instructor- 6 rationale was that if the students make an attempt to solve the problem, they should get something, and therefore up to $75 \%$ credit was given for a problem if a student solved half of the problems correctly. In discussions, it was found that there are significant differences between the grading philosophies of the instructors and this is a major source of difference in the final grades issued in a class. The work of a " $\mathrm{C}$ " student in the eyes of one instructor could as easily be an "A" or " $\mathrm{F}$ " in the eyes of another instructor. Table 3 shows that the ABC rate, class GPA, and course GPAW dropped sharply in fall 2011 for the section taught by Inst-6. The following two semesters, Inst-6 continued the closed book policy for the exams, but the exams were written and graded by the instructor of the course. Table 3 shows that the ABC rates, GPA, and GPAW were higher than the section taught in fall 2011, but lower than those taught during the first three semesters. Comparing the data for the last two sections of course taught by Inst- 6 with those for all NTT instructors, it shows close agreements for the respective ABC rates, GPA, and GPAW values.

Table 3. Grade distribution history for sections of ME 3293 taught by Inst-6

\begin{tabular}{|l|c|c|c|c|c|c|c|c|c|c|c|}
\hline \multirow{2}{*}{ Periods teaching the course } & $\begin{array}{c}\text { \# of } \\
\text { students }\end{array}$ & $\begin{array}{c}\% \\
\mathrm{~A}\end{array}$ & $\begin{array}{c}\% \\
\mathrm{~B}\end{array}$ & $\begin{array}{c}\% \\
\mathrm{C}\end{array}$ & $\begin{array}{c}\% \\
\mathrm{D}\end{array}$ & $\begin{array}{c}\% \\
\mathrm{~F}\end{array}$ & $\begin{array}{c}\% \\
\mathrm{~W}\end{array}$ & $\begin{array}{c}\% \\
\text { ABC }\end{array}$ & $\begin{array}{c}\% \\
\text { DFW }\end{array}$ & GPA & GPAW \\
\hline First three semesters & 75 & 27 & 33 & 21 & 5 & 7 & 7 & 81 & 19 & 2.73 & 2.55 \\
\hline Fourth semester (fall 2011) & 90 & 7 & 11 & 23 & 21 & 18 & 20 & 41 & 59 & 1.60 & 1.28 \\
\hline Last two semesters & 141 & 9 & 21 & 33 & 11 & 11 & 15 & 63 & 37 & 2.07 & 1.76 \\
\hline Combined six semesters & 306 & 13 & 21 & 27 & 12 & 12 & 14 & 61 & 39 & 2.12 & 1.81 \\
\hline All NTT instructors & $\mathbf{4 9 1}$ & $\mathbf{1 4}$ & $\mathbf{1 9}$ & $\mathbf{2 8}$ & $\mathbf{1 2}$ & $\mathbf{1 2}$ & $\mathbf{1 4}$ & $\mathbf{6 2}$ & $\mathbf{3 8}$ & $\mathbf{2 . 1 6}$ & $\mathbf{1 . 8 4}$ \\
\hline All nine instructors & $\mathbf{2 4 4 4}$ & $\mathbf{1 0}$ & $\mathbf{1 6}$ & $\mathbf{2 5}$ & $\mathbf{1 3}$ & $\mathbf{1 5}$ & $\mathbf{1 9}$ & $\mathbf{5 3}$ & $\mathbf{4 7}$ & $\mathbf{1 . 9 3}$ & $\mathbf{1 . 5 7}$ \\
\hline
\end{tabular}


The fate of unsuccessful students is summarized in Table 4. For those taking the class for the first time (including those who repeat the course in the future), the overall GPA over the 55 sections offered is 2.09 and the overall GPAW is 1.64. The overall ABC and DFW rates are $54 \%$ and $46 \%$, respectively. This shows that nearly half of the students on the first attempt will either repeat the class or change majors. If they return for a second attempt, the average GPA and GPAW do not improve, but fall to 1.75 and 1.48, respectively. Also the DFW rate increases slightly to $49 \%$. Overall, students who repeat the course do not do as well as those who take the class for the first time. The GPA and GPAW trends continue downward for those who repeat the course again with a third or more attempts. Things don't improve for those who fail the course.

Table 4. Grades of students on first, second, third, fourth and 5-9 attempts in ME 3293

\begin{tabular}{|c|c|c|c|c|c|c|c|c|c|c|}
\hline \multirow{2}{*}{ Grade } & \multicolumn{2}{|c|}{ First attempt } & \multicolumn{2}{|c|}{ Second Attempt } & \multicolumn{2}{|c|}{ Third Attempt } & \multicolumn{2}{|c|}{ Fourth Attempt } & \multicolumn{2}{|c|}{$5^{\text {th }}-9^{\text {th }}$ Attempts } \\
\hline & Number & $\%$ & Number & $\%$ & Number & $\%$ & Number & $\%$ & Number & $\%$ \\
\hline A & 211 & 13 & 39 & 7 & 9 & 4 & 3 & 2 & 1 & 2 \\
\hline B & 257 & 17 & 86 & 15 & 42 & 9 & 13 & 9 & 4 & 9 \\
\hline $\mathrm{C}$ & 368 & 24 & 162 & 29 & 69 & 32 & 19 & 14 & 6 & 13 \\
\hline $\mathrm{D}$ & 174 & 11 & 100 & 18 & 29 & 13 & 35 & 25 & 7 & 15 \\
\hline $\mathrm{F}$ & 199 & 13 & 91 & 16 & 42 & 19 & 46 & 33 & 20 & 3 \\
\hline $\mathrm{W}$ & 331 & 22 & 89 & 51 & 27 & 12 & 22 & 16 & 8 & 17 \\
\hline $\mathrm{ABC}$ & 836 & 54 & 287 & 49 & 120 & 55 & 35 & 25 & 11 & 24 \\
\hline DFW & 704 & 36 & 280 & 51 & 98 & 45 & 103 & 75 & 35 & 76 \\
\hline Total & 1540 & 100 & 567 & 100 & 218 & 100 & 138 & 100 & 46 & 100 \\
\hline GPA & 2. & & & & & & & & & \\
\hline GPAW & 1. & & & & & & & & & \\
\hline
\end{tabular}

Table 5 explores how those who repeat the course fair in the class for each instructor. It compares the passing rates, GPA, and GPAW for students who attempted the course for the first time and those who have repeated the course more than once. The first time attempts include students who passed the course on the first try plus those who did not pass, but it does not include those attempting the course attempting the course for the second time. Similarly the second attempts include students who passed the course on the second try plus those who did not pass, but it does not include those attempting the course for the third time. The third attempts, fourth attempts follow the same procedure. Table5 displays a much lower passing rate, GPA, and GPAW for students who are repeating the course. It is usually assumed that some students will avoid taking a class from an instructor who has a reputation for being hard, and likewise they will seek to take a class from an easy instructor. Table 5 does not clearly demonstrate suggest such a trend, but it shows that only $29 \%$ of students in Inst-4 sections were first attempter; realizing that Inst-4 has been the toughest grader. On the other hand higher percentage of students sections offered by NTT instructors were first attempters. However it is possible that students did not have too much option of selecting an instructor, since only one section of ME 3293 has been offered every semester, except in the last three semesters. Since ME 3293 is a prerequisite for other courses in thermal sciences or fluid mechanics, students have to take the course in order to progress in their degree program. 
Table 5: Percent of class repeating ME 3293 and percent of repeaters who pass

\begin{tabular}{|c|c|c|c|c|c|c|c|c|c|c|}
\hline \multirow[b]{2}{*}{ Inst \# } & \multirow[b]{2}{*}{$\begin{array}{l}\text { Inst. } \\
\text { Type }\end{array}$} & \multirow[b]{2}{*}{$\begin{array}{c}\text { Total } \\
\text { Number }\end{array}$} & \multicolumn{4}{|c|}{ First attempts by students } & \multicolumn{4}{|c|}{ Students repeating the course } \\
\hline & & & $\%$ Total & $\begin{array}{l}\mathrm{ABC} \\
\text { rate }\end{array}$ & GPA & GPAW & $\%$ Total & $\begin{array}{c}\mathrm{ABC} \\
\text { rate }\end{array}$ & GPA & GPAW \\
\hline 1 & TT & 925 & $37 \%$ & $88 \%$ & 2.64 & 2.44 & $67 \%$ & $31 \%$ & 1.30 & 0.98 \\
\hline 2 & TT & 538 & $41 \%$ & $82 \%$ & 2.68 & 2.43 & $59 \%$ & $29 \%$ & 1.55 & 0.97 \\
\hline 3 & TT & 250 & $29 \%$ & $78 \%$ & 2.49 & 2.15 & $71 \%$ & $19 \%$ & 0.78 & 0.64 \\
\hline 4 & TT & 179 & $45 \%$ & $89 \%$ & 2.62 & 2.41 & $55 \%$ & $36 \%$ & 1.41 & 1.18 \\
\hline 5 & TT & 61 & $43 \%$ & $88 \%$ & 2.97 & 2.61 & $57 \%$ & $39 \%$ & 1.58 & 1.10 \\
\hline \multicolumn{2}{|c|}{ Total TT } & 1953 & $59 \%$ & $85 \%$ & 2.63 & 2.39 & $61 \%$ & $29 \%$ & 1.29 & 0.94 \\
\hline 6 & NTT & 306 & $45 \%$ & $82 \%$ & 2.65 & 2.34 & $55 \%$ & $44 \%$ & 1.65 & 1.38 \\
\hline 7 & NTT & 121 & $55 \%$ & $93 \%$ & 2.67 & 2.51 & $45 \%$ & $35 \%$ & 1.50 & 1.17 \\
\hline 8 & NTT & 49 & $41 \%$ & $90 \%$ & 3.15 & 3.15 & $59 \%$ & $32 \%$ & 1.40 & 0.97 \\
\hline 9 & NTT & 15 & $60 \%$ & $67 \%$ & 2.43 & 1.89 & $40 \%$ & $50 \%$ & 2.20 & 1.83 \\
\hline \multicolumn{2}{|c|}{ Total NTT } & 491 & $47 \%$ & $85 \%$ & 2.70 & 2.44 & $53 \%$ & $42 \%$ & 1.61 & 1.30 \\
\hline \multicolumn{2}{|c|}{ TT and NTT } & 2442 & $40 \%$ & $85 \%$ & 2.60 & 2.40 & $60 \%$ & $31 \%$ & 1.32 & 1.01 \\
\hline
\end{tabular}

It is quite clear from Table 5 that a high percent (85\%) of students pass the course during the first attempt. However the section passing rates are much lower, since the sections include students who are repeating the course for the second time and as high as nine times.

\section{B. ME 4293: Thermodynamics-II}

ME 4293-Thermodynamics-II was offered 42 times and taught by five different instructors between fall semester 1994 and fall semester 2012. One section of the course was offered every spring and fall semester until spring 2011. Starting fall 2011, more than one section of this course has been offered in fall and spring semester. The course has been offered during summer sessions, periodically. Figure 2 displays $\mathrm{ABC}$ rates assigned by various instructors teaching $\mathrm{ME}$ 4293from fall 1994 through fall 2012. The instructors are identified as Inst-1, Inst-2, Inst-3, Inst6, and Inst-10. Four of the instructors were the same instructors who also taught ME 3293 identified earlier as instructors $1,2,3$, and 6 . They are identified with the same numbers in this section. A non-tenure track instructor, identified as Inst-10, also taught the course for two semesters. Figure 2 shows small variations in the passing rates for individual instructors from semester to semester. But the figure displays much wider variation of student passing rates among the five instructors. Student passing rates have been as low as $48 \%$ for a section taught by Inst- 2 and as high as $96 \%$ for another section taught by Inst- 6 . The majority of the section of ME 4293 is taught by Inst-2, followed by Inst-1. The ABC rates and GPAW values were comparable for the Inst-1, Inst-2, and Inst-10. They were lower for Inst-3 and much higher for Inst-6, who was the most lenient grader of ME 3293 also.

From fall 2004, through fall 2012, there have been 1587 attempts in ME 4293 by 1219 students. A total of 958 students $(79 \%)$ attempted the course once, $180(15 \%)$ attempted twice, $64(5 \%)$ attempted three times, $14(1 \%)$ attempted four times, 3 attempted five times, and 1 attempted six times. These data indicate a higher percentage of students attempted ME 4293 only once (79\%) as compared to ME 3293(63\%). Again, it should be noted that the number of students for each 
attempt category does not indicate that all students in that category have passed the course. For example, the 958 students who attempted the course once so far include those students in fall 2012 sections who did not pass the course, but have not attempted the course for the second time.

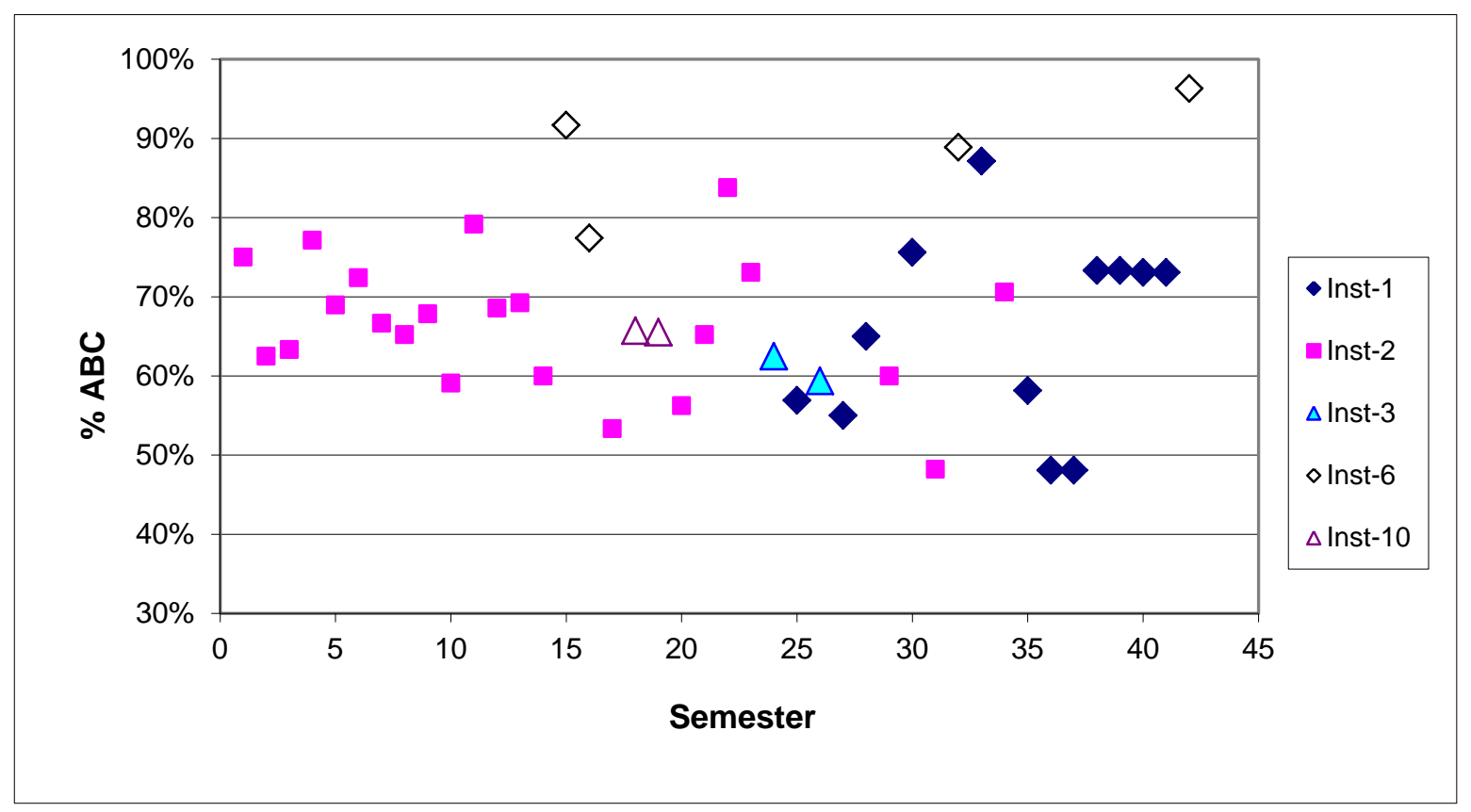

Fig. 2. Percentage of passing grades (A, B, and C) in ME 4293 between fall 1994 and fall 2012

The grade distribution for combined sections of the ME 4293 offered between fall semester 1994 and summer fall 2012 is presented in Table 6. The table shows that for the combined sections, $69 \%$ of students completed the course successfully and $31 \%$ students were unable to do so. It should be noted that UTSA changed its grading system in fall 2011 that now includes plus (+) and minus letter grades. Table 6 shows the points assigned to each letter grade. The ABC rates include grades between $\mathrm{C}$ - and $\mathrm{A}+$, while $\mathrm{DFW}$ includes grades between $\mathrm{F}$ and $\mathrm{D}+\mathrm{A}$ comparison Table 1 and Table 6 shows a higher ABC rate for ME $4293(69 \%)$ than the one for ME 3293 (53\%).

Table 7 shows the average grade distribution for each instructor who taught ME 4293 from fall 1994 through 2012. The instructors included three TT and two NTT faculty members. Table 7 identifies the number of semesters and the total number of students taught by each instructor. Again two types of grade point averages are included in Table 7 for each instructor. All plus and minus grades are reported as a single letter grade. For example the \% B includes grades of B-, B, and B-. Again the standard class grade point average is identified as GPA where grades of W do not have any influence on the values of GPA. Grades of $\mathrm{W}$ are treaded as grades of $\mathrm{F}$ for the calculation of GPAW.

A comparison of the data in Table 7 shows very close agreements for ABC rates and GPAW values among Inst-1, Inst-2, and Inst-10. The ABC rate and GPAW value are lower for Inst-3, 
suggesting again a tougher grader instructor. The ABC rate and the GPAW value for Inst- 6 are much higher than those for other instructors. Table 2 also showed that Inst-3 was the toughest grader and Inst-6 was the most lenient grader.

Table 6. Cumulative grade distribution for all sections of ME 4293 taught from fall 2004 through fall 2012

\begin{tabular}{|c|c|c|c|}
\hline Grade & Points & Numbers receiving the grade & \% of the total receiving the grade \\
\hline $\mathrm{A}+$ & 4.00 & 0 & $0 \%$ \\
\hline $\mathrm{A}$ & 4.00 & 186 & $12 \%$ \\
\hline $\mathrm{A}-$ & 3.67 & 4 & $0 \%$ \\
\hline $\mathrm{B}+$ & 3.33 & 12 & $1 \%$ \\
\hline $\mathrm{B}$ & 3.00 & 332 & $21 \%$ \\
\hline $\mathrm{B}-$ & 2.67 & 18 & $1 \%$ \\
\hline $\mathrm{C}+$ & 2.33 & 25 & $2 \%$ \\
\hline $\mathrm{C}$ & 2.00 & 482 & $30 \%$ \\
\hline $\mathrm{C}-$ & 1.67 & 38 & $2 \%$ \\
\hline $\mathrm{D}+$ & 1.33 & 0 & $0 \%$ \\
\hline $\mathrm{D}$ & 1.00 & 193 & $12 \%$ \\
\hline $\mathrm{D}-$ & 0.67 & 0 & $0 \%$ \\
\hline F & 0 & 127 & $8 \%$ \\
\hline W & 0 & 170 & $11 \%$ \\
\hline Total ABC & & $\mathbf{1 0 9 7}$ & $\mathbf{6 9 \%}$ \\
\hline Total DFW & & $\mathbf{4 9 0}$ & $\mathbf{3 1 \%}$ \\
\hline
\end{tabular}

Table 7. Cumulative grade distribution for sections of ME 4293 taught by each instructor

\begin{tabular}{|c|c|c|c|c|c|c|c|c|c|c|c|c|c|}
\hline $\begin{array}{c}\text { Inst } \\
\#\end{array}$ & $\begin{array}{c}\text { Inst- } \\
\text { Type }\end{array}$ & $\begin{array}{c}\text { \# of } \\
\text { semesters }\end{array}$ & $\begin{array}{c}\text { \# of } \\
\text { students }\end{array}$ & $\begin{array}{c}\% \\
\text { A }\end{array}$ & $\begin{array}{c}\% \\
\text { B }\end{array}$ & $\begin{array}{c}\% \\
\text { C }\end{array}$ & $\begin{array}{c}\% \\
\text { D }\end{array}$ & $\begin{array}{c}\% \\
\text { F }\end{array}$ & $\begin{array}{c}\% \\
\text { W }\end{array}$ & $\begin{array}{c}\% \\
\text { ABC }\end{array}$ & $\begin{array}{c}\% \\
\text { DFW }\end{array}$ & GPA & GPAW \\
\hline 1 & TT & 12 & 673 & 11 & 22 & 39 & 16 & 7 & 7 & 70 & 30 & 2.12 & 1.96 \\
\hline 2 & TT & 22 & 663 & 13 & 20 & 34 & 11 & 8 & 14 & 67 & 33 & 2.21 & 1.89 \\
\hline 3 & TT & 2 & 72 & 6 & 18 & 38 & 8 & 17 & 14 & 61 & 39 & 1.85 & 1.60 \\
\hline $\begin{array}{l}\text { TT } \\
\text { Cumulative }\end{array}$ & $\mathbf{3 6}$ & $\mathbf{1 4 0 8}$ & $\mathbf{1 1}$ & $\mathbf{2 0}$ & $\mathbf{3 7}$ & $\mathbf{1 3}$ & $\mathbf{8}$ & $\mathbf{1 1}$ & $\mathbf{6 8}$ & $\mathbf{3 2}$ & $\mathbf{4 . 1 4}$ & $\mathbf{1 . 9 1}$ \\
\hline 6 & NTT & 4 & 115 & 22 & 52 & 14 & 2 & 1 & 10 & 88 & 12 & 3.02 & 2.73 \\
\hline 10 & NTT & 2 & 64 & 13 & 20 & 33 & 11 & 17 & 4 & 66 & 34 & 2.00 & 1.88 \\
\hline $\begin{array}{l}\text { NTT } \\
\text { Cumulative }\end{array}$ & $\mathbf{6}$ & $\mathbf{1 7 9}$ & $\mathbf{1 8}$ & $\mathbf{4 1}$ & $\mathbf{2 1}$ & $\mathbf{5}$ & $\mathbf{7}$ & $\mathbf{8}$ & $\mathbf{8 0}$ & $\mathbf{2 0}$ & $\mathbf{2 . 6 5}$ & $\mathbf{2 . 4 2}$ \\
\hline $\begin{array}{l}\text { TT and } \\
\text { NTT }\end{array}$ & $\mathbf{4 2}$ & $\mathbf{1 5 8 7}$ & $\mathbf{1 2}$ & $\mathbf{2 3}$ & $\mathbf{3 4}$ & $\mathbf{1 2}$ & $\mathbf{8}$ & $\mathbf{1 1}$ & $\mathbf{6 9}$ & $\mathbf{3 1}$ & $\mathbf{2 . 2 0}$ & $\mathbf{1 . 9 7}$ \\
\hline
\end{tabular}

Table 8 summarizes the grade distributions in ME 4293 during the first, second, third, fourth, and fifth through $6^{\text {th }}$ attempts. There have been 1219 students who have attempted ME 4293 at least once. Among these students $72 \%$ of them completed the course with the grades of A, B, or C. Those students who had not passed the course, but attempted the course for the second time 
are excluded from this group. The GPAW for this group of students was 2.09. For group of students who have repeated the course at least twice, the ABC passing rate and GPAW dropped to $57 \%$ and 1.56 , respectively.

Table 8: Grades of students on first, second, third, fourth and 5and 6 attempts in ME 4293.

\begin{tabular}{|c|c|c|c|c|c|c|c|c|c|c|}
\hline \multirow{2}{*}{ Grade } & \multicolumn{2}{|c|}{ First attempt } & \multicolumn{2}{|c|}{ Second Attempt } & \multicolumn{2}{|c|}{ Third Attempt } & \multicolumn{2}{|c|}{ Fourth Attempt } & \multicolumn{2}{|c|}{$5^{\text {th }} \& 6^{\text {th }}$ Attempts } \\
\hline & Number & Percent & Number & Percent & Number & Percent & Number & Percent & Number & Percent \\
\hline A & 179 & $15 \%$ & 8 & $3 \%$ & 3 & 45 & 0 & $0 \%$ & 0 & $0 \%$ \\
\hline B & 298 & $24 \%$ & 47 & $18 \%$ & 14 & $17 \%$ & 3 & $18 \%$ & 0 & $0 \%$ \\
\hline $\mathrm{C}$ & 405 & $33 \%$ & 93 & $36 \%$ & 34 & $42 \%$ & 10 & $59 \%$ & 3 & $33 \%$ \\
\hline $\mathrm{D}$ & 130 & $11 \%$ & 49 & $19 \%$ & 13 & $16 \%$ & 1 & $6 \%$ & 0 & $0 \%$ \\
\hline $\mathrm{F}$ & 77 & $6 \%$ & 32 & $12 \%$ & 10 & $12 \%$ & 3 & $18 \%$ & 5 & $56 \%$ \\
\hline $\mathrm{W}$ & 130 & $11 \%$ & 32 & $12 \%$ & 7 & $9 \%$ & 0 & $0 \%$ & 1 & $11 \%$ \\
\hline $\mathrm{ABC}$ & 882 & $72 \%$ & 148 & $57 \%$ & 51 & $63 \%$ & 13 & $77 \%$ & 3 & $33 \%$ \\
\hline DFW & 337 & $28 \%$ & 113 & $43 \%$ & 30 & $37 \%$ & 4 & $23 \%$ & 6 & $67 \%$ \\
\hline Total & 1219 & $100 \%$ & 261 & $100 \%$ & 81 & $100 \%$ & 17 & $100 \%$ & 9 & $100 \%$ \\
\hline GPA & & & & & & & & & & \\
\hline GPAW & & & & & & & & & & \\
\hline
\end{tabular}

\section{Tracking Student Performance}

In previous sections it was shown that grade distributions can vary a great deal for the sections of the same course, depending on which instructor taught that section. In this section students who have successfully completed ME3293-Thermodynamics-I with each individual instructor are tracked into ME 4293-Thermodynamics-II. The data is shown in Table 9. As before, the first four instructors are TT and the last four are NTT. Only those students who passed ME3293 are tracked. The grade distribution and ME-3293-GPA are computed. For example, Inst-1 had a passing GPA of 2.66 based on 438 students, of which $18 \%$ earned "A", 30\% "B" and 52\% "C" grades. For these students, 307 successfully completed Thermodynamics II on their first attempt. The distribution of "A", "B" and " $\mathrm{C}$ " grades are comparable in percentages and the passing GPA is also comparable. The table shows that those students who have completed ME 3293 with Inst3 and Inst- 6 performed best in ME 4293. However, the majority of students who completed ME 3293, also took ME 4293 from the same instructor. It is suggested that this data supports the assertion that earning a passing grade in Thermodynamics I from Inst-3 is a strong indication that you are well prepared for the next class, Thermodynamics II. For most NTT faculty, there is a different story. First, it should be highlighted that the number of students are fewer for the NTT, so it is more difficult to make strong assertions about the interpretation of the data. With that in mind, the following trends appears: (1) the NTT faculty issue higher grades as shown by the GPA of those passing Thermodynamics I, (2) the subsequent GPA in Thermodynamics II is distinctly lower. This supports the assertion that the higher grades awarded by the NTT faculty are not indications that student learning was higher, yet to the contrary it supports the assertion that NTT are prone to issue higher grade distributions. Some call this grade inflation and it is understandable since NTT faculty may not be invited back to teach if the perception is that they are not good instructors. By issuing high grades, the department's pass rates are higher. As a 
result, both administrators and students are often happy with these trends especially if the institution has an emphasis on prompt "graduation rates". About the only one unhappy would be the instructor with a reputation of being rigorous who happens to be teaching the subsequent course and those students facing the daunting task of passing Thermodynamics II having learned little in Thermodynamics I.

The observed trend between the TT and NTT is persistent as one considers "all attempts" of Thermodynamics II. Students having passed Thermodynamics I with TT faculty have higher GPA and pass rates than for students having passed Thermodynamics II with NTT faculty. Although the number of students being tracked for the NTT faculty, it is asserted that the trend is supported.

ME 4294 passing rates after the first, second, or third or more attempts are display in Fig. 3 for each group of students who have completed ME 3293 with one of the instructors a through 9. Instructor 5 is omitted, since this instructor taught ME 3293 very recently and there are not sufficient data available to track students into ME 4293. The figure exhibits very close passing rates on the first attempt by students who have completed ME 3293 with TT faculty (Inst-1 through 4). The first attempt passing rates in ME 4293 for students who completed the ME 3293 with Inst-6 and Inst-7 were lower, even though the students received much higher grades in ME 3293.

\section{Conclusions}

This paper explored the relationship between the student learning in Thermodynamics I and subsequent performance in Thermodynamics II. It is shown that grades are highly dependent on the instructor teaching the course. Based on analysis of data from 1994 to 2012, and Thermodynamics I being taught 55 times by nine instructors, the data shows that (1) NTT faculty issue higher grades, and (2) students passing the Thermodynamics I with NTT are less prepared for Thermodynamics II. This data refutes the conclusion that NTT faculty are better instructors with superior teaching skills. The data shows that the NTT faculty have a more lenient grading policy, overall. This study concludes that grades remain the primary overall indicator of student learning, where a high grade indicated superior mastery of the material and a failing grade indicates otherwise. This student highlight that the instructor who issues the grades needs to be considered when looking a grades. A high passing grade from NTT faculty may be equivalent to an average passing grade from TT faculty for the same course. This conclusion is supported by evaluation of grades in two thermodynamics courses where feedback from students is that learning in the first is important to doing well in the second. 
Table 9- Tracking student performance from ME 3293 to ME 4293 for each instructor of ME 3293.

\begin{tabular}{|c|c|c|c|c|}
\hline Inst \# & Inst. Type & & ME 3293 & $\begin{array}{l}\text { ME 4293, successful completion, } \\
\text { first attempt }\end{array}$ \\
\hline \multirow{6}{*}{1} & \multirow{6}{*}{ TT } & Number & 438 & 438 \\
\hline & & A & $18 \%$ & $14 \%$ \\
\hline & & B & $30 \%$ & $23 \%$ \\
\hline & & $\mathrm{C}$ & $52 \%$ & $33 \%$ \\
\hline & & DEF & $0 \%$ & $70 \%$ \\
\hline & & GPA/GPAW & $2.66 / 2.66$ & $2.26 / 2.07$ \\
\hline \multirow{6}{*}{2} & \multirow{6}{*}{ TT } & Number & 208 & 208 \\
\hline & & $\mathrm{A}$ & $23 \%$ & $16 \%$ \\
\hline & & B & $34 \%$ & $21 \%$ \\
\hline & & $\mathrm{C}$ & $43 \%$ & $32 \%$ \\
\hline & & DEF & $0 \%$ & $31 \%$ \\
\hline & & GPA/GPAW & $2.79 / 2.79$ & $2.33 / 2.01$ \\
\hline \multirow{6}{*}{3} & \multirow{6}{*}{ TT } & Number & 83 & 83 \\
\hline & & A & $10 \%$ & $25 \%$ \\
\hline & & B & $41 \%$ & $29 \%$ \\
\hline & & $\mathrm{C}$ & $49 \%$ & $27 \%$ \\
\hline & & DEF & $0 \%$ & $19 \%$ \\
\hline & & GPA/GPAW & $2.60 / 2.60$ & $2.61 / 2.52$ \\
\hline \multirow{6}{*}{4} & \multirow{6}{*}{ TT } & Number & 99 & 99 \\
\hline & & A & $19 \%$ & $13 \%$ \\
\hline & & $\mathrm{B}$ & $22 \%$ & $26 \%$ \\
\hline & & $\mathrm{C}$ & $58 \%$ & $24 \%$ \\
\hline & & DEF & $0 \%$ & $37 \%$ \\
\hline & & GPA/GPAW & $2.61 / 2.61$ & $2.35 / 1.95$ \\
\hline \multirow{6}{*}{5} & \multirow{6}{*}{ NTT } & Number & 28 & 28 \\
\hline & & $\mathrm{A}$ & $29 \%$ & $11 \%$ \\
\hline & & $\mathrm{B}$ & $25 \%$ & $18 \%$ \\
\hline & & $\mathrm{C}$ & $47 \%$ & $43 \%$ \\
\hline & & DEF & 46 & $28 \%$ \\
\hline & & GPA/GPAW & $2.85 / 2.85$ & $2.04 / 2.04$ \\
\hline \multirow{6}{*}{6} & \multirow{6}{*}{ NTT } & Number & 129 & 129 \\
\hline & & $\mathrm{A}$ & $20 \%$ & $19 \%$ \\
\hline & & $\mathrm{B}$ & $37 \%$ & $39 \%$ \\
\hline & & $\mathrm{C}$ & $43 \%$ & $38 \%$ \\
\hline & & DEF & $0 \% \%$ & $13 \%$ \\
\hline & & GPA/GPAW & 2.78 & $2.71 / 2.51$ \\
\hline \multirow{6}{*}{7} & \multirow{6}{*}{ NTT } & Number & 74 & 74 \\
\hline & & $\mathrm{A}$ & $24 \%$ & $7 \%$ \\
\hline & & B & $30 \%$ & $19 \%$ \\
\hline & & $\mathrm{C}$ & $46 \%$ & $51 \%$ \\
\hline & & DEF & $0 \%$ & $23 \%$ \\
\hline & & GPA/GPAW & $2.78 / 2.78$ & $2.17 / 1.91$ \\
\hline \multirow{6}{*}{8} & \multirow{6}{*}{ NTT } & Number & 27 & 27 \\
\hline & & $\mathrm{A}$ & $44 \%$ & $11 \%$ \\
\hline & & $\mathrm{B}$ & $19 \%$ & $26 \%$ \\
\hline & & $\mathrm{C}$ & $37 \%$ & $41 \%$ \\
\hline & & DEF & $0 \%$ & $22 \%$ \\
\hline & & GPA/GPAW & $3.07 / 3.07$ & $1.75 / 1.4$ \\
\hline
\end{tabular}


Table 9. Tracking student performance from ME 3293 to ME 4293 for each instructor of ME 3293 (continued)

\begin{tabular}{|c|c|l|c|c|}
\hline Inst \# & Inst. Type & & ME 3293 & $\begin{array}{c}\text { ME 4293, successful completion, } \\
\text { first attempt }\end{array}$ \\
\hline \multirow{4}{*}{9} & \multirow{3}{*}{ NTT } & Number & 5 & 5 \\
\cline { 3 - 5 } & & $\mathrm{A}$ & $40 \%$ & $0 \%$ \\
\cline { 3 - 5 } & $\mathrm{B}$ & $40 \%$ & $0 \%$ \\
\cline { 3 - 5 } & & $\mathrm{C}$ & $20 \%$ & $60 \%$ \\
\cline { 3 - 5 } & & $\mathrm{DEF}$ & $0 \%$ & $40 \%$ \\
\cline { 3 - 5 } & & GPA/GPAW & 3.20 & $1.75 / 1.40$ \\
\hline
\end{tabular}

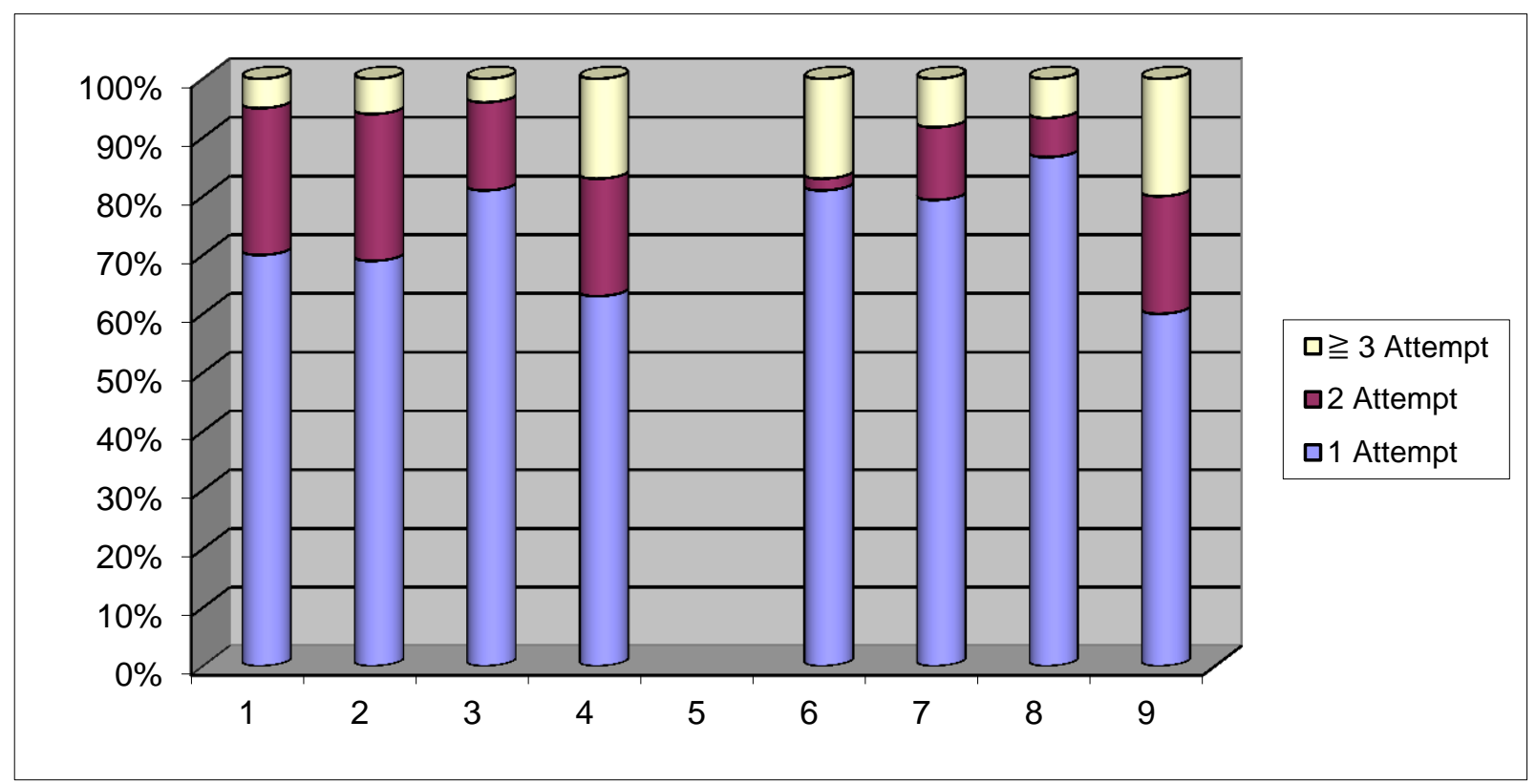

Fig. 3 Passing rates in ME 4293 after first second, or three more attempts by students who have completed ME 3293 with instructors I through 8.

\section{REFERENCES}

[1] Manteufel, R and Karimi, A. "A Meaningful Grade Point Average that Counteracts Grade Inflation," ASEEGSW-T1B-5, Proceedings of the 2011 ASEE-GSW section Annual Conference, March 9-11

[2] Manteufel, R and Karimi, A." Grade-Based Correlation to Identify Effective Static Instructor," ASEE-20102189, Proceedings of the 2010 ASEE Annual Conference, June 20-23, Louisville, KY.

[3] Karimi, A. and Manteufel, R., “Are Grades Good indicators of Students' Depth of Knowledge?” Proceedings of the 2012 ASEE-GSW section Annual Conference, El Paso, Texas, April 4-6, 2012.

[5] Bailey, R.T., "Shouldn't I get an A?," Proceedings of the 2002 ASEE Southeastern Section Annual Meeting, Gainesville, FL, April 4-5, 2002

[6] Johnson, V.E., An alternative to traditional GPA for evaluating student performance, Statistical Science, 12(4): 251-278, 1997.

[7] Felton, J. and P. T. Koper, Nominal GPA and Real GPA: A Simple Adjustment that Compensates for Grade Inflation, Assessment \& Evaluation in Higher Education, 30(6):561-569, 2005.

[8] Manteufel, R. and Karimi, A. "Assisting Adjunct faculty using Committee Exam," ASEE-2012-4742, Proceedings of the 2012 ASEE Annual Conference, June 10-13, San Antonio, Texas. 